\title{
Historiography of Mathematics from the Mathematician's Point of View
}

\author{
Viktor Blåsjö
}

\section{Contents}

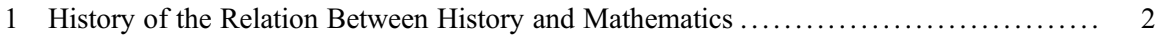

2 The Role of Present Mathematics in Historiography .............................. 9

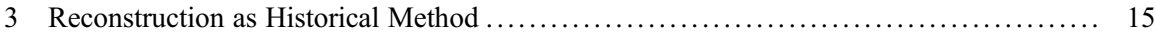

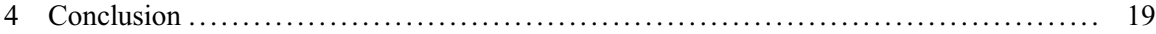

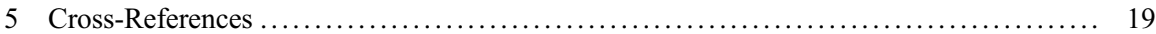

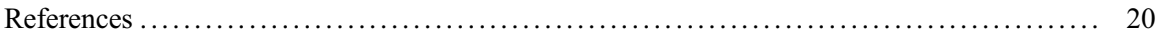

\section{Abstract}

Mathematicians used to be highly invested in the study of the history of their own field, but their voice in historiographical discussions has diminished in influence in the past century. One prominent narrative paints this as a justified fall from grace: mathematicians wedded to present mathematical values looked at the past with prejudiced eyes, whereas a new generation of historians were better able to appreciate the past proper, in its own terms. But the best internalist mathematical historiography of old needed no such external corrective. It was already committed to avoiding presentism and anachronism, for reasons that were not in opposition to mathematical values but rather derived directly from a positive vision of the role that history could play in the mathematical community. In this vision, a historical understanding of how a field developed is a proxy for first-hand research experience in that field. It follows that it is essential for historical accounts to thoroughly convey the scope and limitations of alternative conceptions and approaches, including dead-end developments, since this is precisely what sets the critical knowledge gained by first-hand research experience apart from the doctrinal knowledge gained merely from a textbook. Hence, from this point of view, presentist historiography is not the natural outlook of the mathematician, but rather a direct antithesis of the mathematician's most fundamental

V. Blåsjö $(\bowtie)$

Universiteit Utrecht, Utrecht, The Netherlands

e-mail: V.N.E.Blasjo@uu.nl 
reason for studying history. To study past mathematics precisely as it appeared to active researchers at the time is not foreign to the mathematician, but a direct corollary of the mathematician's core conviction that only those with first-hand research experience in a field of mathematics truly understand it. A sophisticated internalist historiography derived from these ideals was articulated to a greater extent in the past than is commonly recognized today. By going back to its roots, the mathematician's historiography could revive some of the virtues that have been neglected in recent years.

\section{Keywords}

Historiography $\cdot$ Internalism $\cdot$ Presentism $\cdot$ History of the history of mathematics

\section{$1 \quad$ History of the Relation Between History and Mathematics}

The "right" way to study history depends on what one wants historical inquiry to achieve. Historiographic practices - such as using modern mathematical concepts when analyzing past thought - are not inherently good or bad, but can only be judged relative to the intended goals of historical scholarship. To be able to say how we should do history, we must therefore first understand why we do history at all. So to understand the mathematician's relation to history, we must first ask ourselves: What purposes does history serve to the mathematical community? To answer this question, it will be instructive to look at some snapshots of how the relationship between mathematics and history has evolved over time.

In a way, mathematics can be regarded as inherently ahistorical. "Mathematics is ... under the spell of the belief in its objective nature. ... Motives [for undertaking particular investigations] are often more hidden than revealed" since "it is not the style of mathematics to speak about subjective things." But experience shows that the Platonic dream of achieving disembodied perfection is alas "a chimera." By contrast, Aristotle "laid out with the greatest care how thinkers before him thought about all the matters he was dealing with, and with this kind of comparative study saw how he might make a better start towards obtaining general norms." In mathematics, as much as in any other field, this suggests the value of "didactical diagnosis and therapy, on the basis of historical analyses, where these analyses serve only to turn one's attention in the right direction." History "can steer one's attention to differences and conceptual distinctions which would never come to mind by way of direct, abstract considerations." (Toeplitz 1926/2015, 308-309).

The "Platonic" perspective is thus absolutist. It aims for a state of finality and timeless perfection. History is antithetical to its purposes: it aims precisely to transcend that element of human fallibility with which past thought is contaminated. The "Aristotelian" perspective, by contrast, does not aspire to deny or erase the situatedness of knowledge. Instead, it sees past and present thought as inherently intertwined. This conflict remains at the heart of history of mathematics. Mathematicians dream of "the perfect embodiment of immutable laws," while historians are 
all but defined by a "moral commitment to recording and remembering the earthly, perishable detail"; truly, "our muses ... haunt us with their divergent demands" when we try to do justice to both of these perspectives (Guicciardini 2018, 148-150).

Aristotle's disciple Eudemus wrote a history of geometry - the first known treatise on the history of mathematics. The work itself is no longer extant but its overall outlook can be surmised from surviving fragments and references. Eudemus seems to have envisioned his history of geometry being used as a starting point for methodological reflection, similar to how Aristotle engaged with the views of earlier philosophers to articulate his own systems. In part, Eudemus seems to have aspired to present a kind of historical raw data to serve as the basis for such reflection, but he was evidently not shy to add interpretative analysis as well. Thus, his approach is in part comparative rather than purely chronological; he passes judgement on past mathematics, and crafts a narrative of cognitive evolution toward higher states of knowledge, culminating in the mathematics of his own time (Zhmud 2017).

The Aristotelian perspective, then, emphasizes history but treats it instrumentally. History is not expounded for its own sake, but as part of an articulation and analysis of present thought in the field. Mathematical authors of all ages have found it useful to deploy history in such a role. Lagrange and Bourbaki, for instance, incorporated extensive historical notes in treatises where they advanced systematizations of previous knowledge and reconceptualizations of mathematical fields.

This way of utilizing history to inform a systemic survey of a body of knowledge was perhaps especially natural in classical antiquity, when mathematics and philosophy advanced rapidly and were fundamentally transformed. Authors further removed from creative frontiers may take a more antiquarian approach to historical material. One may think, for instance, of how Eutocius, in the sixth century, meticulously catalogued a dozen different cube duplications by various past mathematicians (Netz 2004, 273-306) while showing few, if any, aspirations beyond simply amassing the material.

In the seventeenth century - another vastly creative and transformative era - it was again à la mode to situate research contributions in a potted historical narrative. Major works such as Descartes's Géométrie (1637), Wallis's Algebra (1685), and Newton's Principia (1687) all open by immediately characterizing their projects relative to a particular interpretation of what "the ancients" had done in the subject.

The seventeenth century had no time to produce any full-scale histories of mathematics. The eighteenth century took up this task with enthusiasm, producing several sprawling histories packed with information. After the creative explosions of the seventeenth century, the direction of mathematical research was now on a relatively stable and monotonous trajectory. Once again history was no longer needed to help envision major reconceptualizations of the field, but more to keep track of a growing body of accumulated work. This also fit with the fashion of the day in the sciences and intellectual work generally, which embraced massive encyclopedic surveys, cabinets of curiosity overloaded with assorted knick-knacks, and Baconian accumulation of empirical raw data (Goldstein 2008). Indeed, Montucla's Histoire des Mathématiques (1758) repeatedly references Francis Bacon in its preface. 
As biology focused on gathering any and all specimens and sorting them into descriptive taxonomies, so history of mathematics was likewise preoccupied with assembling masses of material (Bullynck 2016, 10). "Lacroix's history of eighteenth-century analysis can be seen as the culmination of the eighteenth-century tradition of narrative mathematics. Coverage, rather than coherence, was his major goal." (Richards 2006, 707). Similarly, "Kaestner's four-volume Geschichte der Mathematik (1796-1800) is essentially a description of the author's large mathematical library, so that a malicious reviewer could dispatch Kaestner with the words that he seems to have written his work on the book ladder." (Stäckel 1900, 252). Historical works of this time largely assume that direct acquaintance with primary sources is a feasible next step following a standard education from current textbooks (Dauben and Scriba 2002, 88), so that the task of the historian is to survey and summarize rather than to interpret or explain.

As the quantity of mathematical publications grew rapidly, history answered "a need amongst mathematicians for information about who produced which piece of mathematical knowledge when"; in particular, "it would be one task of the historian of mathematics to attribute mathematical credit to the right person." (Schneider 1992, 620-621). "The preoccupation at this early stage in the history of the history of mathematics was an almost exclusive interest in 'priorities' - in mathematical 'firsts'." (Dauben 1999, 4).

Such "firsts"-oriented historiographies effectively assume that the development of mathematics is cumulative rather than conceptually transformative. Only then is a one-to-one matching of each tenet of present mathematics with some past work possible. Because of the conceptual stability of eighteenth-century mathematics, this view was sustainable for a while. But in the nineteenth century, it was quickly becoming obvious that mathematics was no longer progressing purely by adding knowledge, but by systematically reorganizing entire theories in ways that made much earlier work obsolete. Thus, the enterprise of encyclopedic "firsts"-oriented history lost its purpose. "In the current state of analysis we may regard these discussions [of past mathematics] as useless, for they concern forgotten methods, which have given way to others more simple and more general," Lagrange observed in 1806. Lacroix made a similar point in his Essais sur l'enseignement (1805): "to educate students in the ways of [historical] authors, even the most celebrated of them, must cease because since they wrote, the science has made progress which has completely changed the connections of the propositions and often their language." (Richards 2006, 709-710).

In response, the nineteenth century saw a revival of fortunes of the Platonic ideal of mathematics as historically disembodied perfect reason. Mathematical exposition should follow "purely rational principles," Lacroix observed as a contrast to his rejection of the utility of historical perspectives. Cauchy, setting the tone for decades to come,

reconceptualized and restructured mathematics to be rigorous rather than narrative. ... Cauchy's definitional precision effectively separated mathematics from the rest of human 
thought. ... Cauchy clearly recognized this. The separation of mathematical argument from human reason was essential to his rigorous program. (Richards 2006, 700, 712)

This vision of mathematical rigor left little or no place for the relevance of history to mathematical understanding.

The end of the nineteenth century saw of resurgence of interest in the history of mathematics. The new generation noted how they had to break free from the antihistory sentiments widespread in the mathematical community:

\begin{abstract}
When I began to study mathematical and historical research about 30 years ago, most of the mathematicians I came into contact with thought that thorough research in this field was a waste of time, so that such work should not be considered meritorious but rather reprehensible. Now, however, such a view may be regarded as a curiosity, and most of my colleagues in the field agree that that the history of mathematics is not only relevant in itself, but also has great educational value for the study of mathematics, and that the understanding of it can often be useful even for the advancement of science. (Eneström 1900, 4)
\end{abstract}

This increased status of history can be attributed to internal mathematical developments (Stäckel 1900, 251): foundational mathematical research in the late nineteenth century undermined the simplistic notion of an absolute (and ahistorical) standard of rigor and truth, thereby reversing the rationale for anti-historicism of rigorization movements such as that of Cauchy.

History also gained new appeal as mathematics fragmented into more specialized subfields. Specialized research mathematics can often only be understood by one's closest colleagues. History, by contrast, provides a rich store of mathematical material that is accessible and interesting to all mathematicians. Therefore "one of the advantages in the study of the history of mathematics is to bring colleagues together" (Struik 1980, 24) around shared experiences and interests. Thus it became a selling point of the field that "only historical thinking can form a counterweight against the much-lamented specialisation" that was becoming more and more marked in contemporary research (Neugebauer 1927, 44).

Increased specialization also meant that that mathematicians more frequently found themselves teaching or engaging with mathematical theories with which they had little direct experience in their own research and personal mathematical practice. In such cases, there would often be an abundance of solid sources for picking up the necessary technical content, but these could often not convey the same sense of the lay of the land that an insider with hands-on experience in the field would have. History can be a substitute for this kind of first-hand experience. Retracing the thought of the pioneers of the field is a digest surrogate for personal experience. Without this perspective of what a field looks like to the active researcher, it is easy to misjudge the purpose and importance of ideas and the connections between them. "The historical investigation of the development of a science is most needful, lest the principles treasured up in it become a system of halfunderstood prescripts, or worse, a system of prejudices." (Mach 1883/1919, 255).

It was commonplace to argue that students of mathematics "must naturally follow the same course of development on a smaller scale, that the science itself has taken 
on a larger" (Klein 1896, 248). In other words, mathematics education should follow the biological principle that key stages in the evolutionary history of a species are often recapitulated in the fetal development of each individual organism (Cajori 1896, v; Poincaré 1899, 159; Klein 1932, 268). Another sign of the unity of research and educational work envisioned at the time is that, in the nineteenth century, "in a remarkable number of cases research work in mathematics [was] stimulated by a perceived educational need: the new theory appeared more in textbooks and lecture notes than in ordinary papers." (Grattan-Guinness 1990, 155). Lectures by, for instance, Monge, Cauchy, and Weierstrass spun off entire research programs. History and teaching had a natural place in mathematics: the educator, the historian, and the research strategist shared a common goal in understanding the gist of existing work in a field, the scope and limitations of its methods, and the connections and motivations of its key ideas.

The early twentieth century was a golden age - "the most distinguished period" (Grattan-Guinness 1990, 150) - for the status of history in the mathematical community. At its peak as a world-leading research center, the Mathematical Institute at Göttingen offered a rich range of advanced courses on history of mathematics taught by leading mathematicians (Toeplitz 1926/2015, 303; Tobies 2019, 412-413). In Frankfurt, top mathematicians and students came together for in-depth seminars on a range of specialized topics in history of mathematics every semester from 1922 to 1935 (Siegel and Lenzen 1979, 224-226). Affordable editions of important primary sources in the history of mathematics aimed at the learned public sold well, as a historical perspective on mathematics was seen as befitting "every educated reader" (Dauben and Scriba 2002, 127, 130-131). History was pursued as "an honorable thing to do," and not for dogmatic ideological reasons such as an "attempt to legitimize the new mathematics by identifying it with the core element of the tradition" (Gray 2008, 372).

In this context, a new generation of mathematical historians emerged. But it was a rude awakening for the mathematical community to realize the ramifications of its neglect of history in the preceding decades. When mathematicians had turned their back on the history of mathematics in the nineteenth century, philosophers and cultural theorists had picked up the slack. The old eighteenth-century encyclopedic histories of mathematics, "understood only by professional mathematicians" (Dauben and Scriba 2002, 13), did not meet the needs of the nineteenth century. Mathematicians had abandoned history just as the transformative developments of the early nineteenth century created a need for higher-order narratives offering prominent interpretative syntheses (Bullynck 2016). Authors from humanistic fields had been happy to fill this void with works that integrated history with grand epistemological or sociocultural theories. But excessive enthusiasm for such macro perspectives had led to factual errors as well as neglect and ignorance of sources (Brentjes 2016, 50; Høyrup 2016, 65; Dauben and Scriba 2002, 19).

The new generation of mathematical historians were keen to position themselves in opposition to the excesses of the humanistic histories of the nineteenth century. An instinctive aversion to any attempts at grander "synthesis" was a natural part of this reaction (Neugebauer 1951/1969, viii; Rowe 2016, 139), as was a greatly increased 
emphasis on primary mathematical sources (Dauben and Scriba 2002, 135). Propagation of errors and lack of scholarly rigor was also seen as a major threat to the status of historical scholarship (Eneström 1912/13). The fear was often expressed that mathematicians in particular might see history as an unserious field.

If mathematicians who are not historians see that even highly praised mathematicalhistorical works contain a large number of unreliable data and uncritical statements, they easily get the impression that the history of mathematics does not yet exist as a real science, and that no special knowledge or training is needed to write a mathematical-historical work. If they then have any reason to want historical articles on certain mathematical subjects, it may easily happen that they turn to persons for this purpose who lack certain very important prerequisites for truly scientific research in the field of mathematics and history. (Eneström $1908 / 09,9)$

Moritz Cantor's multivolume Geschichte der Mathematik (1877-1901) became a focal point for these concerns, and stood as a symbol for the style of history that had resulted when mathematicians neglected the field (Lützen and Purkert 1994, 1-7).

Its total lack of mathematic competence as well as its moralizing and anecdotal attitude seriously discredited the history of mathematics in the eyes of mathematicians, for whom, after all, the history of mathematics has to be written. ... Had [Cantor] studied the texts themselves, he would have avoided countless misinterpretations and inaccuracies which have become commonplace. (Neubegauer 1956)

Attacks on Cantor's history such as this were reiterated again and again in the early twentieth century, as the new generation of mathematical historians saw this as a crucial contrast defining their distinctive historiography.

The efforts to rehabilitate history of mathematics in the eyes of mathematicians and revive its status as an integral part of mathematics itself in the early twentieth century were successful. But this was soon disrupted by war and fascism. When the continental model of university and $\mathrm{PhD}$ education was exported to other parts of the world, great emphasis was placed on the importance of leading students to the frontiers of original research (Turner 2020, 58). This had indeed been one element that set the $\mathrm{PhD}$ system and academic culture at the world-leading continental universities apart from the wider geographic range of academic institutions that now quickly rose to greater research prominence. However, broader intellectual elements of the tradition were largely discarded in this process. The outlook that sophisticated historical and philosophical awareness is essential even for a wellrounded understanding of mathematics itself had won considerable traction at leading continental institutions, but emerging academic institutions building up their rapidly expanding research infrastructure did not continue this trend.

Hence a new generation of more narrowly trained research specialist mathematicians emerged. Insofar as they addressed history, they did so with less humility, less historical and philosophical awareness, and greater overconfidence in the superiority of their own style of mathematics. In this way, they exposed themselves to critiques from historians. It became easy for historians coming from humanities disciplines to 
dismiss mathematicians dabbling in history as naively writing "without consideration of basic questions of historiography" (Grattan-Guinness 1990, 157). A standard narrative emerged, alleging that the second half of the twentieth century brought "a new and more sophisticated historiography," whereas older work on the history of mathematics was commonly marked by rampant presentism and simple-minded priority questions. In older work, allegedly,

the effect was to "explain" the subject in anachronistic concepts and terminology, to select topics for study only insofar as they had a connection to more recent developments, and to praise or damn these efforts on the basis of whether they anticipated (took a step toward) the current state of mathematical knowledge.

In the "new historiography," by contrast,

the focus is on understanding the thought of the period, independent of whether it is right or wrong by today's account. The historiography is more philosophically sensitive in its understanding of the nature of mathematical truth and rigor, and it recognizes that these concepts have not remained invariant over time. (Kitcher and Aspray 1988, 24-25)

This narrative was very agreeable to a new generation of historians of science who "wanted independence from the sciences" and sought "to supply their own agenda for their discipline rather than accepting that of the scientist" (Lightman 2016 , 2). In this way, they could characterize their own historiography as an objective improvement of standards, and the historical outlook of mathematicians as inherently naive. This basic framing remains fundamental in historiographical discussions to this day (even though, to be sure, actual professional affiliations are more fluid and complex than a neat terminological division into "mathematicians" and "historians" might suggest; Goldstein 1995, 7).

Historical circumstances facilitated over-universalization of this narrative. The single-minded focus on specialized research in the twentieth-century growth spurt of academic institutes of mathematics, often in places that had little tradition of intellectual history, produced a neglect of historical appreciation among mathematicians. What could better be regarded as a legitimate critique of this contingent circumstance has instead all too often been perceived as proof of an intrinsic fault inherent in any internalist-mathematical approach to history.

In the early twentieth century, history was a notable presence in elite mathematical culture. Leading mathematical historians were deeply anchored in this culture rather than coming from separate academic departments. This state of affairs was driven by a deeply felt conviction in the mathematical community of the rich and multifaceted ways in which history can be of integral value to the mathematical enterprise. This era set out the beginnings of what may be called a critical internalist historiography of mathematics.

History was not as central to subsequent mathematical generations. Having lost touch with the intellectual roots that informed the turn-of-the-century vision of history and its purpose within mathematics, many mathematicians reverted back to 
the more simplistic views of history that had been commonplace in earlier centuries. This may be called a presentist internalist historiography of mathematics.

Critical internalism emphasized the parallels between historical understanding and creative mathematical research. The same skill of grasping the forces that have shaped a field is equally essential in historical scholarship and in the context of formulating an informed and forward-looking mathematical research program of one's own. To learn a new field is to reenact the course of its evolution in one's own mind; to digest the argument of a past work of mathematics is to feel precisely that tension between research goals and the tools available that the working mathematician of that time struggled with: this is an analog in the domain of historical scholarship of the view that the research-active mathematician of today has an authoritative claim to understanding of their field qualitatively different from any dilettante outsider account, no matter how descriptively and factually accurate. In this way, history is key to develop understanding of new fields, and to form critical judgements about it based on independent thought.

Presentist internalism, on the other hand, does not accord history any such parity of authority with present research. Critical and presentist internalisms are both committed to the ideal of active research experience as the sine qua non of mathematical understanding. But critical internalism interprets this ideal inclusively, and sees history as a way to effectively, in distilled form, obtain more of that precious form of understanding than we could have time for through conventional personal research. Presentist internalism demotes history from this perch. By conceiving the ideal of the primacy of active research understanding narrowly, to include current mathematical research only, it cuts off the critical internalist rationale for seeing history as an integral part of mathematical thought itself.

It is unfortunate that these two very different approaches are so often conflated. Much historiographical discussion in the second half of the twentieth century was framed in terms of a fundamental dichotomy between internalist-mathematical approaches on the one hand and properly historical approaches on the other. Critiques of the internalist-mathematical approach have naturally focused on the faults of presentist internalist historiography, under the mistaken impression or insinuation that this undermines internalist approaches altogether. The above contextualization suggests instead that, rather than attributing historiographic naiveté to inherent characteristics of the mathematical psyche, a better way to understand the mathematician's relation to history is in terms of the purposes history can serve to the mathematical community (Barany 2020, 1077).

\section{The Role of Present Mathematics in Historiography}

The mathematician's way of doing history is often portrayed as historiographically flawed in that it distorts past thought through the use of anachronistic perspectives and presentist interpretative biases. Indeed, it is often suggested that it was not until historians took over the field from mathematicians in the latter half of the twentieth 
century that this rampant problem was recognized and cured (Unguru 1975; Rowe 1996, 10).

However, this diagnosis applies only to presentist internalism. Far from being inherent in any internalist approach, anachronism and presentism were strongly condemned by the critical internalists, long before they became a fault line of twentieth-century historiographic debates. Nesselmann, who studied mathematics under Jacobi before turning to history, put it clearly long ago:

Nothing is more usual and natural when reading ancient works than our substituting the standpoint of the ancient authors with our own, ... [so that] it is one of the most difficult tasks of the historian to understand and convey the conceptual background not only of each author, but also of each period of time in its individual character, and at the same time to keep the modern viewpoint in mind, without lifting the ancient author from his peculiar sphere of thinking into our present one. (Nesselmann 1842, 37-38; Smadja 2015, 229)

The same point was repeated over and over again in the critical internalist context.

There is nothing more common and natural, especially when reading older works, than to substitute one's own point of view for that of the author, and to take for granted that the knowledge and insights we are familiar with are also taken for granted by that author, and to 'read into' him things he never thought of. It is therefore absolutely necessary to distinguish clearly the conclusions drawn from the words of an author from his own expressions. (Stäckel 1900, 255)

This strong rejection of anachronism and presentism was no mere lip service, but a fundamental recognition that these historiographic vices were in direct conflict with several of the core purposes the critical internalists intended history to serve in the broader landscape of mathematical thought.

The critical internalist ideal was that of "truly historical thinking united with personal research activity [in mathematics]." "Somewhat like history of philosophy," the history of mathematics must combine the genuinely historical with the "spirit" of research in the field itself. If it does, "even the purely professional mathematician would stand to gain from engagement with it"; if not, it will be relegated to "an entirely meaningless separate existence." (Neugebauer 1927, 39, 44). It is precisely because critical internalist history of mathematics intends to make a genuine contribution in the domain of actual mathematical thought that it must not be subservient to modern mathematics. For if historical scholarship merely passively mirrors the values of modern mathematics, it would be redundant to mathematicians and hence doomed to a "meaningless separate existence" in their eyes. Genuinely historical scholarship, on the other hand, could make relevant contributions to the mathematician by putting existing conceptions in an unexpected light, and to uncover and clarify illuminating connections between them, which is exactly what new research mathematics does.

The value of history for obtaining a form of understanding somewhat analogous to that gained through active research became all the more relevant as specialization increased. The more mathematics grew, the more mathematicians found themselves 
having to engage with areas of mathematics in which they had no personal research experience. This drove home to them the insight that "it is impossible to grasp even one mathematical concept without having assimilated all the concepts which led up to its creation, and their connections" (Klein 1928, 1). To address this, one of the goals of historical scholarship was to recreate a distilled equivalent of first-hand research experience at a certain time and with certain tools.

[History requires] acquainting oneself so well with the notions and procedures in use at that time that one is able to judge what could be achieved within the area known at the time and under the given conditions, and moreover by examining what these tools have in fact been used for. A thorough understanding will not be obtained until one finds a complete connection between the usability of the tools at their disposal and the range of the results they gained with them. (Zeuthen 1903, 555; Lützen and Purkert 1994, 16)

This describes not only sound historical methodology but also, and equally, the mindset of a mathematician immersing themselves in a foreign research field, or conscientiously preparing to teach a course in an area outside their expertise.

It is evident already from these considerations that an approach to history that is only interested in identifying precursors of one's preexisting notions is profoundly antithetical to critical internalist historiography - indeed, it immediately voids the core motivations for studying history at all. This applies to many other critiques of presentist internalist historiography as well.

It is common to contrast the mathematician's selective interest only in work that turned out to be important in hindsight with the historian's equal attention to dead ends and ideas that did not go anywhere (Grabiner 1975, 439-440; Grattan-Guinness 2011, 4). Again, nothing could be further from the goals of critical internalist historiography. The core aim of history to provide a critical perspective and sense of research-problem dynamic for parts of mathematics outside one's direct expertise depends very essentially on an understanding of the limitations of alternative approaches.

Not only a knowledge of the ideas that have been accepted and cultivated by subsequent teachers is necessary for the historical understanding of a science, but also that the rejected and transient thoughts of the inquirers, nay even apparently erroneous notions, may be very important and very instructive. (Mach 1883/1919, 254-255)

The historical study of the sciences must not only be concerned with tracing the progress of the human mind in the knowledge of truth, but also with recalling its errors; it is precisely the healthy appreciation of these errors which alone can make the true importance of the sciences clear. (Tannery 1930,3)

In this respect, it is precisely the study of approaches that do not map neatly onto modern ones that is mathematically enlightening, and hence the particular interest of mathematicians who want history to be relevant to their concerns.

It is certainly of interest to know when an idea or method that is part of present mathematics reached a form in which we immediately recognise it, or when a technique whose utility we now know was first used. But it is of greater interest to pay attention to those ideas and 
methods that diverge from present ones. ... The modern method will generally have far more extensive uses, and it will be stated in rules that can be applied purely mechanically; but precisely because the related older methods were not so designed, but rather had to be adapted to each case, they could led to a deeper penetration and a more versatile investigation than the corresponding modern treatment. The mere fact that the less developed form required a greater effort of thought led to observations that would easily escape one who now reach the same main result with railroad speed. (Zeuthen 1903, 554-555)

The critical internalist approach sees the study of the history of mathematics as in many ways analogous to original mathematical research. "Whoever wants to find something new must often free themselves from finished rules, and this can be learnt from those who have not yet organised their procedures into finished rules." (Zeuthen 1903, 554-555). Just as mathematical innovation often consists in getting a firm grasp of ideas that are "in the air," so also historical understanding depends on that same talent to perceive the essence in a bustling body of burgeoning work (Weil 1978, 438). On a more big-picture scale, forming a clear overview of the development of ideas in a field up to a certain point is a task common to both the historian and the mathematician setting out an original research program, suggesting that mathematicians (especially research strategists) and historians of mathematics share skillsets and interests (Weil 1978, 436-437). These analogies work only if past mathematics is understood in its own terms, including its challenges and limitations as they appeared at the time. Only then is historical research analogous to mathematics research. All of these analogies break down completely if past mathematics is merely mined for precursors of modern ideas or is presumptuously judged by their degree of agreement with modern theories. This again shows why such presentist perspectives are anathema to critical internalism.

Supporting these goals often involves interpreting and clarifying past mathematics in modernized form. The historian's "most important function as far as the study of mathematics itself is concerned" is that of "studying and analyzing the works of the great mathematicians throughout history in order to make those works accessible to modern readers and researchers" (Edwards 2020, 66). Mathematics should be useful "above all to the mathematicians who are its most reliable consumers and the creators of its raw material" (May 1975, 450). Of course, "when a professional mathematician wants to cultivate the history of his science, he must, obviously, first of all submit to the rules that apply to everyone who wants to know the historical truth." But the goals of the historian and the mathematician are not incompatible. On the contrary, the mathematician can "contribute something of his own" to historical analysis by bringing current mathematical tools to bear on illuminating past thought.

In very different expressions one can recognize the same truths. ... In this way, the mathematically educated cultivator of the history of mathematics has the opportunity to interpret texts which otherwise seem to be incomprehensible, or which have been misunderstood, to find connections among historical statements which otherwise may seem to be concerned with different things, to detect the preparation of a discovery which otherwise seems to have been due to the unique gift of prophecy of one single ingenious man, and above all to find and understand the coherence in the research and knowledge of a given period and thereby its connection to the points of view of the earlier and later periods from or 
to which impulses are given. Not only will historical knowledge thereby increase and be consolidated but one will gain exactly that type of knowledge of old mathematics that will give the greatest benefit for mathematicians and pedagogues. (Zeuthen 1917, 201-202; Lützen and Purkert 1994, 17)

Such analyses must of course be careful to avoid the traps of anachronism. But the mere potential fallibility of the mathematician's method of analysis is no reason to abandon it; other historical methods have equal pitfalls of their own.

It is not uncommon for past mathematicians to present their work in a way that differs substantially from that of modern science, and this can lead one to pay too little attention to the real train of thought when studying a text, so that one reads the modern view into the presentation. ... By going back to the sources [and remaining close to the original form of expression], a mathematical-historical author will of course be able to avoid certain mistakes [of anachronism], but it is very possible that he will be guilty of other and perhaps even greater mistakes [such as deficiencies of mathematical understanding]. (Eneström 1911/12, 6-8)

The only foolproof way to avoid misrepresentation is to reproduce the original expressions verbatim, without commentary or analysis, but this would serve only to make the historian superfluous and capitulate on a major goal of historical scholarship.

Critical internalism has sound tools to avoid the dangers of anachronism. The structural relations between ideas, rather than their superficial surface form, is the truest indicator of their nature and essence.

\footnotetext{
The value of a method used in the past does not depend on the greater or lesser superficial resemblance to those whose utility we now know, but on what they could be - and actually were - used for in their own time. Likewise, reaching a particular result has significance in and of itself; but the discovery of such a result may be more or less coincidental, and the value one should attribute to that discovery at a given time depends on whether the significance of the result, and its uses, were understood at the time. The correct assessment of the various mathematical advances of the past can therefore only be obtained by studying the mathematics of these times as a whole, that is to say by immersing oneself in the then customary ideas and methods. (Zeuthen 1903, 555)
}

The viability of interpretative hypotheses and the faithfulness of modernizing paraphrases should be judged at this deeper level of conceptual analysis rather than by excessive attention to surface form.

This point is much misunderstood. Instead of judging fidelity to historical thought in these sophisticated terms, historians often fall back on adherence to old notation and language as a proxy for non-anachronism - a conceptually simplistic and impoverished notion of historical fidelity (Blåsjö and Hogendijk 2018) that conflates critical with presentist internalism. Thus, historians congratulate themselves that "only comparatively recently has the practice of translating [historical] works into modern notation become unacceptable," praising the "new and sophisticated literature" that accords with these "historically sensitive" standards (Bertoloni Meli 2006, 9; Blåsjö 2014, 114). It is even claimed that analyzing past thought in modern 
mathematical terms "implies ... a strong affirmation of the superiority of modern ideas over those of the past" (Rowe 1996, 10). But this is exactly contrary to the goals of critical internalism, to which providing a critical perspective on current mathematics is one of the main purposes of historical scholarship in the first place. Critical internalists were always very clear about this:

\footnotetext{
The goal of my mathematical historiography ... requires ... a study that does not assume that our time has become wiser than [past mathematicians] were, but that seeks to learn something from them, and particularly to grasp that [aspect] of their way of thinking which may have been lost during the later generalising development. (Zeuthen 1903, 555-556)
}

Modern historians have been equally critical of the "Aristotelian" mode of engaging with history that uses an analysis of past thought as a basis for formulating new and forward-looking ideas. Cherry-picking historical evidence for self-serving ends is not history but "history-satire" (Grattan-Guinness 1973, 449), or "ransacking history" (Dauben 1994, 7). History proper asks "what happened in the past?" whereas these presentist narratives instead ask "how did we get here?" This is not "history" but "heritage": a self-centered delineation of a "royal road to me" (GrattanGuinness 2004, 164-165).

But this modern dichotomy is too uncharitable a view of the Aristotelian mode of engagement with history. The point of the Aristotelian approach is not to use the present to judge the past, or to use the past to flatter the present. Rather, it is to use the past to conceive and understand the present. The question "how did we get here?" presupposes that the "here" is already fixed before historical inquiry begins, rather than being shaped through historical investigation. The defining characteristic of Aristotelian accounts of history is perhaps not presentism but historicism: instead of condemning such histories as abusing and distorting the past for instrumental ends, we should perhaps praise them for making history an integral part of any creative and critical thought.

The confluence of historical analysis and current thought can be seen as a source of strength and purpose rather than as a threat to historical purity and autonomy. "The historical notes in Bourbaki's Eléments were intended to show the antecedents of his ideas - an important goal, since a reorganization of established theories should be a natural outcome of previous mathematical development and not a rootless caprice." (May 1975, 449). Lagrange did the same "in many of his publications," basing his own systematization of the field and forward-looking research strategy on "excellent examples of serious historical research" (Dauben and Scriba 2002, 72). Indeed, it is natural for the interests of the mathematician and the historian to be united in such enterprises, since an incorrect understanding of past work will lead to a wrong-headed synthesis and hence a research program that fails to learn from the work that has already been done.

Instead of the dichotomy between "good" history pursued with a supposedly pure mind, and "bad" history contaminated by the author's own ideas, we should perhaps question the assumption that historical inquiry could and should be cleanly detached 
from other dimensions of human thought, as such a critique presupposes. Indeed, one could argue that this assumption is a demonstrable logical impossibility.

\begin{abstract}
The idea of forgetting the later past of an historical episode, often put forward as desirable historiography, is impossible to achieve, since the historian has to know which notions are later, and this requires the historical task already to have been accomplished.... We have some historical text before us; say Euclid's Elements. How can we read it in a historical spirit? A popular answer, put forward for all kinds of history, goes as follows. When reading Euclid's work, forget all theories in the field involved that have been developed since; step into his shoes ... and read his work with his eyes. Unfortunately, ... this method suffers from a difficulty; namely, it is completely useless. For in order to ignore all knowledge produced since Euclid one needs to know what that knowledge is in the first place. But in order to know that we must be able distinguish it from the knowledge produced before and during Euclid's time. But in order to know that we need to know the history of Euclid's work - before studying the history of Euclid's work! (Grattan-Guinness 2004, 169, 179)
\end{abstract}

Altogether, the war on anachronism in modern historiography has sometimes been more bark than bite. It is a powerful image that translating past mathematics into modern notation and terminology is an act of unsympathetic erasure and dogmatic self-centeredness. As history of mathematics moved outside mathematics departments, this evocative motif was a neat rallying call for the self-identity of the new generation. Still, it may be fair to say that the number of actual scalps won by this method has been a bit underwhelming compared to the passion with which it has been advocated. Concrete attempts to prove its superiority over the critical internalism of old in specific cases have perhaps on the whole been less resounding than the rhetoric surrounding them (Blåsjö 2016). But if smoking-gun evidence for the culpability of old internalism is in limited supply here, then modern historiographers have had a second major prong of attack, to which we now turn.

\title{
3 Reconstruction as Historical Method
}

Mathematicians can be impatient readers of history. When they approach a text, they tend to ask themselves "what's really going on here?" (Rowe 1996, 9). They may prioritize "a sort of rationally reconstructed or 'distilled' history," dismissing minor aberrations with the cavalier attitude that "actual history is frequently a caricature of its rational reconstructions" (Lakatos 1976, 5, 21; Lakatos 1970).

Modern historians take a diametrically opposite view. Trying to explain why mathematical ideas developed as they did is seen as inherently dubious.

The student of history should not ask such childish queries. His purpose cannot be to give a completely logical account of the past, for such account is obviously out of the question. It is only here and there that a few logical knots can be tied, for the rest, we must be satisfied with a faithful description of the possibilities which materialized. ... The capriciousness of mathematical development cannot be emphasized too much. (Sarton 1957, 18) 
In keeping with this conviction,

whereas the history of science previously stressed a big picture focusing on the theoretical progress made by great scientific heroes ..., the field is now dominated by scholars offering rich, thickly descriptive, local studies. (Lightman 2016, 1)

The mathematician is most interested in higher-order connections between ideas, while the historian finds authenticity precisely in local and idiosyncratic particulars. One may use a biological metaphor to illustrate these contrasting approaches.

[Historical sources can be likened to] the fossils that tell us about life on earth in distant epochs, and just as the palaeontologist dares to reconstruct the fauna and flora of that time on the basis of these remains, one could demand that the historian of mathematics should try to establish the connection of mathematical ideas on the basis of the facts established by exact research and thus to bring that mathematical thought back to life. (Stäckel 1900, 260)

But there are two levels to this enterprise: the global and the local. One concerns an "evolutionary" view of history - trying to relate a given historical occurrence to its precursors and antecedents - while the other is "phenomenological" - striving for the most direct, raw experience of a historical moment in and of itself (Dijksterhuis 1953).

Both are essential for critical internalist history. The phenomenological perspective corresponds to the goal of recreating an authentic picture of the genuine research experience as it appeared to mathematicians of the past.

The historian must re-enact the past in his own mind. ... He must see what the [underlying] problem was, of which his author is here stating his solution. He must think that problem out for himself, see what possible solutions of it might be offered, and see why this particular [author] chose that solution instead of another. (Collingwood 1993, 282-283)

The mathematician's tendency to draw parallels to known modern problem contexts in order to create "useful pasts" (Goldstein 2010) can more charitably be seen as a way of getting at this form of authenticity rather than as a dogmatic translation into a preconceived framework.

The evolutionary perspective is equally needed, since traditional internalism intends history of mathematics to serve a supporting function to mathematical research and understanding. Purposes such as drawing up and critically assessing research programs and educational curricula demand a big-picture view of overarching developments - a need that history is well suited to address. Thus, to the internalist, "truly, the main purpose of the history of the development of mathematics is to provide information about the connection between mathematical ideas." (Eneström 1910/11, 6)

Based on confidence in a fundamental unity of mathematical through across all ages and cultures, mathematicians tend to be optimistic about the possibility of successful reconstructions on both of these levels. 
The paleontologist undertakes to reconstruct the whole organism from scarce remains, assuming that the laws of biology observed in beings living at present have always held. Who would deny that this assumption has proved to be true, that, even if some errors were made, the results of this research are more than an uncontrollable game of the imagination? It seems to be precisely because of the unity of the human spirit that the laws of productive mathematical creation which are currently in force remain applicable to earlier times. (Stäckel 1900, 262)

Today's historians have much less confidence in this assumption of unity of past and present thought, and the ability of a modern mathematician to intuitively empathize with historical thought in a way reliable enough for historical reconstruction. It is felt that the old attempts based on these hubristic assumptions underestimated their own subjectivity, and overidealized and over-linearized the irregular and contingent nature of historical development (Saito 1998, 134; Sidoli $2014,35)$. To avoid these dangers, today it is almost axiomatic - "a kind of nullhypothesis" - "that there is a discontinuity between mathematical thought of the past and that of the present" (Fried 2018, 16). In terms of the biological metaphor, this corresponds to restricting of paleontology to the descriptive, factual level, and treating with great suspicion the possibility of genuinely grasping the lived experience of other organisms, as well as viewing the overall path of evolution as governed more by chance circumstance than explicable rational principles.

These problems were well known to the old generation of critical internalists.

Doesn't one leave the field of science with the demand that the historian should not only represent the content but also the connections of mathematical ideas? Are not the historical facts then replaced by arbitrary and imaginative structures, so that such reconstructions have only subjective value? Certainly, no one will deny that taking this path brings with it great dangers, and it has rightly been warned that philosophical constructions of history made without sufficient expertise have never truly advanced our understanding. Nevertheless, I am convinced that this demand is not only justified, but that it can also be carried out. ... Far from speaking out in favour of unbridled subjectivism, I consider it the right, the duty of the historian to go beyond the 'bare facts', and I am convinced that it is possible to fulfil this demand without having to give up the achievements of the critical school. ... If such conjectures, which of course must always be called conjectures, explain all the facts of a complex of phenomena in a simple way, then one will be able to regard them, just as in the natural sciences, as a stage in the journey from error to truth. (Stäckel 1900, 261-263)

The divergent intuitions of the mathematician and the historian cast the viability of the method of hypotheses in the history of mathematics in very different lights. Historians, inclined to assume major discontinuities between past and present, give great credibility to documents of the time and little to later interpretations. Mathematicians, by contrast, place great faith in the brotherhood of their kind, and feel that the work of a mathematician is better understood by a mathematician of another age than by an outsider who happened to be closer merely in time and space. Already in the days of Zeuthen and Cantor, this conflict was articulated and debated at some length (Lützen and Purkert 1994, 28-33). Similarly, historians are predisposed to seeing idiosyncrasies and the particular, whereas mathematicians have a sense that their field develops almost quasi-deterministically, which implies good prospects for empathetic 
understanding and reconstruction (Paumier and Aubin 2016, 209; Bourbaki 1994, 173). "Beethoven and Shakespeare did unique work, and we would not have Fidelio or King Lear if they have not lived. However, symmetric functions would have been discovered by others if Newton had not lived." (Askey 1988, 202).

Comparing the merits of these incommensurable outlooks objectively is all but impossible, and so is tallying their track records of actual outcomes. One could argue that internalism enjoyed some remarkable predictive successes: the discoveries of Archimedes's lost work The Method and the decoding of Babylonian mathematics, for example, can be regarded as spectacular vindications of hypotheses that had been previously stipulated on purely internalist grounds (Lützen and Purkert 1994, 25; Rowe 1996, 7). On many smaller points as well the critical internalists found that "whether I have been on the right track with [my historical interpretations], my work itself has often given me an opportunity to test" (Zeuthen 1903, 556), seeing themselves vindicated by the results. The necessity of using mathematical understanding to go beyond explicit sources can also be argued from the nature of present mathematics. "For example, Weierstrass's new foundation of the theory of functions was largely spread orally by his students. If a future historian of the nineteenth century would neglect this source of transmission, he would come to completely wrong conclusions." (Stäckel 1900, 261).

But the method of hypotheses has also had its failures. The early twentiethcentury generation is often faulted for being too much under the spell of the mathematics of its own time rather than that of the historical era they were supposed to be studying (Høyrup 2016, 71; Chemla 2012, 21-26; Gray 2008, 373). A notorious example is the alleged crisis in early Greek mathematics resulting from the discovery of incommensurability, or the irrationality of $\sqrt{2}$ - a prominent topic of speculation to the critical internalists generation. Today's historians are inclined to view this as dubious history contaminated by the concerns of the mathematical community at the time - a mere projection of the Grundlagenstreit with Hilbert and Brouwer as the main antagonists (Knorr 2001; Saito 1998, 133).

Indeed, it is probably indisputable in retrospect that the old internalists sometimes let an inflated sense of the mathematical preoccupations of their own time go to their heads and cloud their judgement on historical matters in some cases. But one may note that the critical internalist historiographical program contains within it the tools to cure this problem. Namely, in its oft-repeated principle that history should be a vehicle for a critical perspective on current mathematical practice.

In addition to anachronistic biases, subjectivity is another charge against the method of reconstruction: "the number of plausible, reconstructed histories is often equal to the number of scholars working along such lines" (Sidoli 2014, 35). This severely undermines the allegedly semi-deterministic and unified character of mathematical development that was invoked to justify the reconstructivist enterprise in the first place. But in this case too, a corrective principle can be derived from within sophisticate internalism itself. The critical internalists were under no delusion that their reconstructions were anything but fallible, but they were confident that lively clashes of bold and clear ideas would be a self-correcting and fruitful enterprise. Daring hypotheses are valuable "if only to provoke further study." "It is the fate of all 
scholarship to be valid only for a few generations; . . . let us stir up as many ideas as we can. Our grandchildren will benefit from this." (Tannery 1889, 496; Pineau 2010, 377). Many modern historians are more likely to greet the proliferation of hypotheses with exasperation than combative enthusiasm. Internalist studies that would be useful in the sense intended by Tannery, assuming an ambient culture of debate, are bound to look reckless in the risk-averse climate of today's historiography. What is constructive in one context is folly in the other. A multitude of competing alternative reconstructions is consistent with a standard conception of scientific progress, and is not in itself proof of a pathological level of subjectivity in the field. Theoretical quantum mechanics was not abandoned in the early twentieth century just because empirical findings were subject to several viable but incompatible interpretations.

In sum, relatively free-wheeling reconstruction as a historical method is naturally associated with the goals and convictions of the mathematician. Although out of fashion historiographically, this may not be a straightforward case of good riddance. Reconstructions may have a checkered track record in some respects, but the core convictions that motivated this enterprise also entail self-correcting mechanisms for overcoming precisely the weaknesses nowadays commonly associated with such approaches.

\section{Conclusion}

Mathematicians lost the historiography wars of the twentieth century and they have only themselves to blame. Due to an increasingly exclusive focus on specialized research productivity, mathematicians lost touch with the ideals that had led to history being accorded a central place in mathematics around the beginning of the century. The critical internalist historiography articulated by that generation gave way to a more simplistic internalism. Historians with a vested interest in wresting the field from the mathematicians pounced on this weakness and portrayed it as irrevocable. Having weakened their commitment to the intellectual unity of mathematical research, education, and historical inquiry, mathematicians were left without the tools to defend themselves. The mathematicians lost the historiography wars not for the fallibility of their approach to history, but for neglect of the ideals on which this approach was founded. The historiography of mathematics may yet have much to gain by reviving these ideals.

\section{$5 \quad$ Cross-References}

Algebraic Versus Geometric Thought and Expression in the Early Calculus

- Education and Mathematical Practice

- Historiography of Mathematical Practice: Mathematics and Power

- Mathematical Practice as Philosophy, with Galois, Riemann, Poincaré, and Grothendieck

- What Happens When We Read a Mathematical Text from a Historical Point of View? 


\section{References}

Askey R (1988) How can mathematicians and mathematical historians help each other? In: Kitcher P, Aspray W (eds) History and philosophy of modern mathematics, Minnesota studies in the philosophy of science XI. University of Minnesota Press, Minneapolis, pp 201-217

Barany MJ (2020) Histories of mathematical practice: reconstruction, genealogy, and the unruly pasts of ruly knowledge. ZDM 52:1075-1086

Bertoloni Meli D (2006) Thinking with objects: the transformation of mechanics in the seventeenth century. Johns Hopkins University Press, Baltimore

Blåsjö V (2014) A critique of the modern consensus in the historiography of mathematics. J Humanist Math 4(2):113-123

Blåsjö V (2016) In defence of geometrical algebra. Arch Hist Exact Sci 70(3):325-359

Blåsjö V, Hogendijk JP (2018) On translating mathematics. Isis 109(4):774-781

Bourbaki N (1994) Elements of the history of mathematics. Springer, Berlin

Brentjes S (2016) Practicing history of mathematics in Islamicate societies in 19th-century Germany and France. In: Remmert VR, Schneider M, Kragh Sørensen H (eds) Historiography of mathematics in the 19th and 20th centuries. Birkhäuser, Basel, pp 25-52

Bullynck M (2016) The history of mathematics in the progress of mankind: modifying the narrative around 1800. In: Remmert VR, Schneider M, Kragh Sørensen H (eds) Historiography of mathematics in the 19th and 20th centuries. Birkhäuser, Basel, pp 9-23

Cajori F (1896) A history of elementary mathematics with hints on methods of teaching. Macmillan, New York

Chemla K (ed) (2012) The history of mathematical proof in ancient traditions. Cambridge University Press, Cambridge

Collingwood RG (1993) The idea of history. Oxford University Press, New York

Dauben JW (1994) Mathematics: an Historian's perspective. In: Sasaki C, Sugiura M, Dauben JW (eds) The intersection of history and mathematics, science networks historical studies XV. Birkhäuser, Basel

Dauben JW (1999) Historia mathematica: 25 years/context and content. Hist Math 26(1):1-28

Dauben JW, Scriba CJ (eds) (2002) Writing the history of mathematics: its historical development. Birkhäuser, Basel

Dijksterhuis EJ (1953) Doel en methode van de geschiedenis der exacte wetenschappen, inaugural address. Utrecht University, Utrecht

Edwards HM (2020) The role of history in the study of mathematics. Math Intell 42:66-69

Eneström G (1900) Ziele und Aufgaben eines Organs für mathematisch-historische Forschung und für aktuelle Fragen auf dem Gebiete der mathematischen Wissenschaften. Bibl Math 1(3):1-7

Eneström G (1908/09) Über kritische Behandlung der Geschichte der Mathematik. Bibl Math 9 (3): $1-14$

Eneström G (1910/11) Über Probleme der mathematischen Geschichtsschreibung. Bibl Math 11(3): $1-10$

Eneström G (1911/12) Über die Bedeutung von Quellenstudien bei mathematischer Geschichtsschreibung. Bibl Math 12(3):1-20

Eneström G (1912/13) Wie kann die weitere Verbreitung unzuverlässiger mathematischhistorischer Angaben verhindert werden? Bibl Math 13(3):1-13

Fried MN (2018) Ways of relating to the mathematics of the past. J Humanist Math 8(1):3-23

Goldstein C (1995) Un theoreme de Fermat et ses lecteurs. Presses Universitaires de Vincennes, Saint-Denis

Goldstein C (2008) How to generate mathematical experimentation and does it provide mathematical knowledge? In: Fest $U$ et al (eds) Generating experimental knowledge. MPIWG, Berlin, pp 61-85

Goldstein C (2010) Des passés utiles: mathématiques, mathématiciens et histoires des mathématiques. Noesis 17:2010 
Grabiner JV (1975) The mathematician, the historian, and the history of mathematics. Hist Math 2(4):439-447

Grattan-Guinness I (1973) Not from nowhere: history and philosophy behind mathematical education. Int J Math Educ Sci Technol 4(4):421-453

Grattan-Guinness I (1990) Does history of science treat of the history of science? The case of mathematics. Hist Sci 28(2):149-173

Grattan-Guinness I (2004) The mathematics of the past: distinguishing its history from our heritage. Hist Maths 31(2):163-185

Grattan-Guinness I (2011) History or heritage? An important distinction in mathematics and for mathematics education. Am Math Mon 111(1):1-12

Gray J (2008) Plato's ghost: the modernist transformation of mathematics. Princeton University Press, Princeton

Guicciardini N (2018) Un altro presente: on the historical interpretation of mathematical texts. BSHM Bull 33(3):148-165

Høyrup J (2016) Mesopotamian mathematics, seen "from the inside" (by Assyriologists) and "from the outside" (by historians of mathematics). In: Remmert VR, Schneider M, Kragh Sørensen, H (eds) Historiography of mathematics in the 19th and 20th centuries. Birkhäuser, Basel, pp 53-78

Kitcher P, Aspray W (1988) An opinionated introduction. In: Kitcher P, Aspray W (eds) History and philosophy of modern mathematics, Minnesota studies in the philosophy of science XI. University of Minnesota Press, Minneapolis, pp 3-60

Klein F (1896) The arithmetizing of mathematics. Bull Am Math Soc 2(8):241-249

Klein F (1928/1979) Vorlesungen über die Entwicklung der Mathematik im 19. Jahrhundert. Teil I., Springer-Verlag, Berlin. Quoted from the English translation, Development of Mathematics in the 19th Century, Math Sci Press, Brookline

Klein F (1932) Elementary mathematics from an advanced standpoint: arithmetic, algebra, analysis, Macmillan, New York, reprinted by Dover Publications

Knorr WR (2001) The impact of modern mathematics on ancient mathematics. Revue d'histoire des mathématiques 7(1):121-135

Lakatos I (1970/1971) History of science and its rational reconstructions. In Buck RC, Cohen RS (eds) PSA 1970: proceedings of the biennial meeting of the philosophy of science association, Boston Studies in the philosophy of science VIII, Springer, Dordrecht, pp 91-136

Lakatos I (1976) Proofs and refutations: the logic of mathematical discovery. Cambridge University Press, Cambridge, UK

Lightman B (ed) (2016) A companion to the history of science. Wiley Blackwell, Chichester, UK

Lützen J, Purkert W (1994) Conflicting tendencies in the historiography of mathematics: M. Cantor and H. G. Zeuthen. In: Knobloch E, Rowe DE (eds) The history of modern mathematics, volume III: images, ideas, and communities. Academic Press, Boston, pp 1-42

Mach E (1883/1919) The science of mechanics: a critical and historical account of its development, Open Court Publishing, La Salle, IL, 1919. First published as Die Mechanik in ihrer Entwickelung historisch-kritisch dargestellt, Leipzig

May KO (1975) What is good history and who should do it? Hist Math 2(4):449-455

Nesselmann GHF (1842) Versuch einer kritischen Geschichte der Algebra I: Die Algebra der Griechen. Reimer, Berlin

Netz R (2004) The works of archimedes, vol 1. Cambridge University Press, Cambridge

Neubegauer O (1956) A notice of ingratitude. Isis 47(1):58

Neugebauer O (1927) Über Geschichte der Mathematik. Mitteilungen des Universitätsbundes Göttingen 9(1927):38-45

Neugebauer O (1951/1969) The exact sciences in antiquity, 2nd edn. Dover Publications, New York

Paumier A-S, Aubin D (2016) Polycephalic Euclid? Collective practices in Bourbaki's history of mathematics. In: Remmert VR, Schneider M, Kragh Sørensen H (eds) Historiography of mathematics in the 19th and 20th centuries. Birkhäuser, Basel, pp 185-218

Pineau F (2010) Historiographie de Paul Tannery et réceptions de son œuvre: sur l'invention du métier d'historien des sciences, PhD dissertation, Université de Nantes 
Poincaré H (1899) La logique et l'intuition dans la science mathématique et dans l'enseignement. L'Enseignement Mathématique 1:157-162

Richards JL (2006) Historical mathematics in the French eighteenth century. Isis 97(4):700-713

Rowe DE (1996) New trends and old images in the history of mathematics. In: Calinger R (ed) Vita mathematica. Mathematical Association of America, Washington, DC

Rowe DE (2016) Otto Neugebauer's vision for rewriting the history of ancient mathematics. In: Remmert VR, Schneider M, Kragh Sørensen H (eds) Historiography of mathematics in the 19th and 20th centuries. Birkhäuser, Basel, pp 123-141

Saito K (1998) Mathematical reconstructions out, textual studies In: 30 years in the historiography of greek mathematics. Revue d'histoire des mathématiques 4(1):131-142

Sarton G (1957) The study of the history of mathematics, and the study of the history of science. Dover Publications, New York

Schneider I (1992) The history of mathematics: aims, results, and future prospects. In: Demidov SS et al (eds) Amphora: Festschrift für Hans Wussing zu seinem 65. Geburtstag. Birkhäuser, Basel, pp 619-629

Sidoli N (2014) Research on ancient Greek mathematical sciences, 1998-2012. In: Sidoli N, Van Brummelen G (eds) From Alexandria, through Baghdad: surveys and studies in the Ancient Greek and Medieval Islamic mathematical sciences in Honor of JL Berggren. Springer, Berlin, pp 25-50

Siegel CL, Lenzen KM (1979) On the history of the Frankfurt mathematics seminar. Math Intell 1(1979):223-230

Smadja I (2015) Sanskrit versus Greek 'Proofs': history of mathematics at the crossroads of philology and mathematics in nineteenth-century Germany. Revue d'histoire des mathématiques 21(1):217-349

Stäckel P (1900) Review of Cantor, M., Vorlesungen über Geschichte der Mathematik. Göttingische gelehrte Anzeigen 162(1):251-264

Struik DJ (1980) Why study the history of mathematics? Undergrad Math Appl J 1:3-28

Tannery P (1889) Review of Paul Tannery, Pour l'histoire de la science hellène. Archiv für Geschichte der Philosophie 2:492-498. Reprinted in Paul Tannery, Mémoires Scientifiques, XI, 360-366

Tannery P (1930) Mémoires Scientifiques, Volume X, (edited by Heiberg JL, Zeuthen HG). Gauthier-Villars, Paris

Tobies R (2019) Felix Klein: Visionen für Mathematik, Anwendungen und Unterricht. Springer, Berlin

Toeplitz O (1926/2015) The problem of University courses on infinitesimal calculus and their demarcation from infinitesimal calculus in high schools. Sci Context 28(2):297-310

Turner LE (2020) Cultivating a research imperative: mentoring mathematics at Stockholms Högskola 1882-1887. Hist Math 50(2020):50-83

Unguru S (1975) On the need to rewrite the history of Greek mathematics. Arch Hist Exact Sci 15(1):67-114

Weil A (1978/2009) History of mathematics: why and how, lecture at the international congress of mathematicians in Helsinki, 1978, reprinted in Oeuvres scientifiques - collected papers III: 1964-1978. Springer, New York

Zeuthen HG (1903) Ved forelæggelsen af "Mathematikkens Historie i 16. og 17. Aarhundrede," In: Oversigt over det Kongelige Danske Videnskabernes Selskabs Forhandlinger. Copenhagen

Zeuthen HG (1917) Hvorledes Mathematiken i tiden fra Platon till Euklid blev rationel videnskab, Det Kongelige Danske videnskabernes selskabs skrifter, Naturvidenskab og Mathematik, Afd. 8, Raekke I.5. Copenhagen

Zhmud L (2017) Eudemus' history of mathematics. In: Bodnar, Fortenbaugh (eds) Eudemus of Rhodes, Rutgers University Studies in Classical Humanities XI. Routledge, New Brunswick, NJ, pp 263-306 